\title{
'JUST KIDDING. I'M WHITE!' KNOWLEDGE, PERCEPTIONS AND ATTITUDES OF WHITE AND INDIAN MALE UNIVERSITY STUDENTS TOWARDS HIV PREVENTION
}

\section{Phebbie Mboti}

Department of Communication Studies

University of Johannesburg

$<>$

\section{Nyasha Mboti}

Department of Communication Studies

University of Johannesburg

nmboti@uj.ac.za

\section{ABSTRACT}

This article reports the findings of a qualitative study that explored what white and Indian students at a South African university felt and knew about HIV prevention. The study explored the knowledge, perceptions and attitudes of white and Indian male students at the University of KwaZulu-Natal's (UKZN) Howard College towards medical male circumcision (MMC) as an HIV prevention procedure. The study was prompted, in part, by a cynical tweet of Justine Sacco, which implied

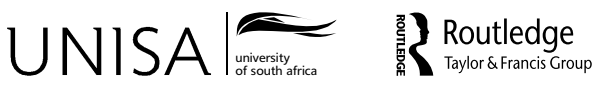


that HIV is an exclusively black disease. More substantially, the research aimed to fill a gap in studies of non-black student demographics with regard to HIV prevention. The level of knowledge and the attitudes of white and Indian male students were explored to establish the acceptability of HIV prevention amongst these two demographics. To what extent do non-black students care about HIV prevention and reflect on HIV prevalence amongst themselves? The prevention method selected for the study was MMC - a choice informed by UKZN's formal adoption and roll out, in 2013, of MMC as its latest HIV prevention strategy for students and staff. The study, which sampled 40 students, was rooted in the Health Belief Model, which explains health behaviour change in terms of barriers, benefits and cues to action, as well as the Social Ecology Model, which recognises the interwoven relationship between individuals and their greater environment. A qualitative, interpretive, exploratory research design was employed. Data were collected using semi-structured interview questions, and analysed thematically. The findings suggest a relatively widespread perception that white and Indian students are not at risk of HIV, demonstrating that the association of HIV with a specific race is both a sad fact and a sign of enduring prejudice and stigma.

Keywords: attitudes, Indian, Health Belief Model, HIV, Justine Sacco, knowledge, medical male circumcision, perceptions, race, Social Ecology Model, white

\section{INTRODUCTION}

This article reports the findings of a qualitative study that explored what white and Indian students at the University of KwaZulu-Natal's (UKZN) Howard College felt and knew about HIV prevention. The study explored the knowledge, perceptions and attitudes of white and Indian male students towards medical male circumcision (MMC) as an HIV prevention procedure. The study, prompted in part by an infamous tweet by Justine Sacco that implied that HIV is an exclusively black disease, intended to explore whether non-black student demographics care about HIV prevention, and the extent to which the selected sample of students reflected on HIV prevalence amongst themselves. How widespread is the attitude that HIV infection and prevention are problems only for Africans? In short, the level of knowledge and the attitudes of white and Indian male students were explored to establish the acceptability of HIV prevention by these two demographics. The research study was rooted in two theoretical models of health: (1) the Health Belief Model (HBM), which explains health behaviour change in terms of barriers, benefits and cues to action; and (2) the Social Ecology Model (SEM), which recognises the interwoven relationship between individuals and their greater environment, and how one influences the other.

\section{BACKGROUND}


South Africa is considered by some to be a race-obsessed nation (Holborn 2010). The racial classification of the Population Registration Act, 1950 (which formally divided South Africans into four race groups: white, Indian, African and coloured), has been retained post-1994. Race as a foundational fact, it seems, just will not go away. This study regarded race as an important factor in the formation of attitudes and perceptions of disease. Bashford, in Imperial hygiene (2004), shows that the colonised were projected as perpetually diseased. The biomedical management of hygiene (Bashford 2004) and contagion (Bashford and Hooker 2001) was (and to some extent still is) often racially motivated.

The study was prompted, in part, by the infamous and cynical (some would say racist) tweet of December 2013 by a white American woman, Justine Sacco, which implied that HIV is an exclusively black disease. Sacco, who has extended family here in South Africa, tweeted the message just before boarding a plane on a visit from New York. Although she received no replies to the tweet in the 30 minutes prior to her flight, the tweet was picked up by social media users who tipped an editor of Gawker's Valleywag tech-industry blog (Ronson 2015). The editor, Sam Biddle, immediately retweeted Sacco's tweet to his 15000 followers. The tweet immediately went viral during Sacco's 11-hour flight from Heathrow, with the hashtag \#HasJustineLandedYet trending worldwide. During this time, tens of thousands of umbrageous tweets responded to Sacco's message.

When Sacco arrived in Cape Town, a few indignant protestors were waiting at the airport to accost her. Sacco, who was later fired from her job in the aftermath of the Twitter storm, immediately instructed a friend to delete her account, and later made a public apology in which she remarked that her tweet had been 'insensitive' and conceded that AIDS 'does not discriminate by race, gender or sexual orientation'. She also pointed out that the disease 'terrifies us all uniformly'. 'I am ashamed,' she said, adding that she was 'very sorry for the pain' she had caused 'to the millions of people living with the virus'. She told Jon Ronson, the author of the book, So you have been publicly shamed (2015): 'Only an insane person would think that white people don't get AIDS.'

Despite her public apology, Sacco justified her actions by saying that '[1]iving in America puts <you? one? $>$ in a bit of a bubble when it comes to what is going in the third world. I was making fun of that bubble.' Whether or not Sacco was misinterpreted, the fact of the matter remains that her tweet suggested that AIDS was a racial disease. The tweet first intimates that Sacco would be in danger of getting AIDS by going to Africa, which exclusively associates AIDS with the African continent. Sacco then clarifies that she is not in any danger of getting AIDS because she is white. She thus appears not only to associate HIV infection with the black race, but also intimates that whites do not need to act on HIV prevention by virtue of their race. How widespread is Sacco's attitude? The study whose findings this article reports, sought to provide some baseline answers. 


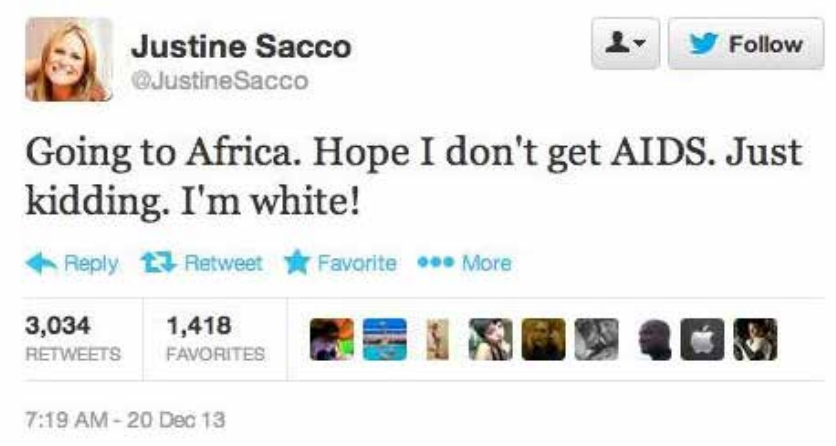

Figure 1: The infamous Justine Sacco tweet

Beyond the Sacco tweet, the research aimed to fill a gap in studies of non-black student demographies with regard to HIV prevention. A predominant number of studies and monographs generally present what Africans know and say about HIV prevention. This is reflected in literature on MMC as a preventive procedure (Naidoo 2012; Peltzer and Mlambo 2012; Shisana, Rehle and Simbayi et al. 2008). The identification of blacks as belonging to a 'high HIV prevalence' demography has made it more convenient for researchers in South Africa (and other locations in Africa) to limit their sample populations to Africans. This has resulted in a Nexus search returning no results for MMC studies focusing on whites or Indians. While a few studies (e.g., HEAIDS 2010; HESA 2008, 29) include race as a significant variable in questionnaires, the reporting of the results only describes findings related to 'Africans' and 'Others'. The study on which this article is based aimed to invert the normative trend of exclusively asking Africans about HIV prevention.

Furthermore, few studies have used race as a variable to study attitudes towards HIV prevention, and whites and Indians in particular remain largely underresearched. The few race-based studies that have been done show interesting results: the report Public attitudes in contemporary South Africa (HSRC 2002), for example, questioned all demographics in South Africa about the perceived risk of contracting HIV. The study sought information on whether Africans, Indians, coloureds and whites in this country thought 'people like themselves could get HIV/AIDS' (HSRC $2002,88)$. White respondents $(46.1 \%)$ showed significantly less perception of risk compared to coloureds (70.3\%), Africans (62\%) and Indians (50\%), (ibid, 85). Of all the demographics represented, whites and Indians 'showed the least concern' about being infected with HIV, at 70.3 and 50 per cent respectively (ibid, 75). Ironically, whites had the highest percentage (95.2) in terms of knowledge of HIV symptoms, transmission and prevention, followed by coloureds $(88.4 \%)$, Indians $(85.3 \%)$ and African (82.9\%). 
It can be surmised, from the data above, that high levels of knowledge regarding HIV symptoms, transmission and prevention do no translate to improved perceptions of risk to self. This suggests that the nature of such knowledge is abstract. What seems clear from the HSRC study is that the whites and Indians sampled tended to view HIV as less their problem. A study by Sakarombe $(2012,24)$ at the University of KwaZulu-Natal concluded that 'the perception that white male students are not risk of HIV is relatively widespread while, by extension, the perception that strategies such as MMC are meant for black men (since HIV/AIDS "is a black issue") is generally held, probably unconsciously'.

The HSRC study suggests that 'race is a significant variable, along with others such as age and LSM' $(2002,89)$, and recommends the need for additional studies to explore how gender and racial identities shape and impact attitudes towards HIV. This angle, the report argues, offers various ways of developing new and useful programmes deemed more efficient in fighting HIV. The HSRC report is important for two reasons: (1) it recommends the need to study social and racial identities, instead of ignoring them; and (2) it further demonstrates that the perception exists that HIV is a disease exclusively targeted at a certain group. The HSRC study was therefore an important point of departure for the research presented here.

Other South African studies pertaining to respondents' knowledge, attitudes and perception seem to gloss over race as a variable. Kincaid and Parker $(2008,7)$, for instance, note of respondents who believe they are not at risk of catching HIV:

Among the $64 \%$ of respondents who believe they are not at risk, almost all gave a rational justification. The answers were unaided, hence they were not a response to a direct question about a specific behaviour: $36 \%$ said they were faithful and/or trusted their partner, $14 \%$ said that they always used a condom, $14 \%$ said that they were abstaining from sex, $4 \%$ said they avoided sex with sex workers, and 3\% said that they did not share needles. In response to a separate question, $18 \%$ said that they used a condom the first time that they had sex. The six responses were combined into a single dichotomous variable referred to below as HIV prevention behaviour.

It is clear from the above citation that none of Kincaid and Parker's reported respondents mentioned their race as a reason why they probably did not perceive of themselves as at-risk. Kincaid and Parker do not cite any respondent considering race a significant variable in constructing the belief that they are immune from catching HIV. This is uncharacteristic, considering South Africans' preoccupation with race (Holborn 2010). This study, carried out at UKZN, regards race as an important factor in the formation of attitudes and perceptions around HIV prevention.

\section{METHODOLOGY}

The HIV prevention method selected for the study was MMC, a choice informed by UKZN's formal adoption and roll-out in 2013 of MMC as its latest HIV prevention 
strategy for students. HIV prevention is a major focus of health communication strategies, interventions and initiatives in South Africa. Not surprisingly, MMC is one of the prevention strategies targeted by public health communication (cf. Brothers for Life campaign). In April 2013, the UKZN AIDS Programme initiated a campaign to advocate for the provision of MMC facilities to the entire university community. The roll-out of the campaign is sufficient proof that MMC is considered integral to attempts to reduce HIV and AIDS transmission within the general university community.

This study posed three key research questions:

1. What do white and Indian male UKZN students know about MMC?

2. How do white and Indian male students perceive MMC?

3. What are the attitudes of white and Indian male students towards MMC?

The study's research questions were all qualitative. Particularly, the questions restricted the investigation to only three specific parameters: knowledge, attitude and perception. The two controlling variables were race (whites and Indians only) and gender (males only). The appropriate research design for the study therefore had to address the 'what' and 'how' exploratory questions as unambiguously as possible, in order to understand the respondents' knowledge, attitudes and perceptions.

Such responses are not easy to measure quantitatively, since they are intangible, uncountable and personal. Also, it is impossible to control knowledge, attitude and perception in a clinical laboratory setting. The ideal approach to exploring knowledge, attitudes and perceptions is therefore qualitative and interpretive (Denzin and Lincoln 2005) - methods which are ideal in situations where not much is known about a problem (Denzin and Lincoln 2005; Terre Blanche and Durrheim 1999). Little is known about the knowledge, attitudes and perceptions of male, white and Indian students towards the HIV prevention procedure of MMC. Together, these factors made the qualitative and interpretive research paradigm the most appropriate for the study. Since little was as yet known about the study problem, the research design was exploratory in nature. Exploratory studies typically 'employ an open, flexible and inductive approach to research as they attempt to look for new insights into phenomena' (Terre Blanche and Durrheim 1999, 39). The main concern of such research designs is to discover a deeper understanding about a particular research problem (Ghauri et al. $1995<$ not in refs>; Philips and Pugh 1987; Webb 1992).

The sampling strategy for the study grew out of four considerations, namely the three research questions, the overall research design, the research method and the research ethics involved. The sample population was drawn from the University of KwaZulu-Natal, Howard Campus. The sampling frame at the college was 496 white male students and 1285 Indian male students. Coloureds, whose student population 
at the college is very low, relative to Africans, whites and Indians, were purposively excluded from the sample. An important issue regarding the sampling frame was to balance the recognition that the sample needed to accurately reflect the population, given that in qualitative research statistical inference is not a core objective. This balance was achieved through purposive theoretical sampling. Finally, the sample population was stratified according to the key demographic variables of gender (i.e., males only) and race (i.e., whites and Indians only).

The reason for stratifying the sample according to gender was that MMC at UKZN and elsewhere was intended strictly for males only. It made sense, in the absence of baseline data, to start with males only. The reason for stratifying the sample according to race was provided by the study rationale, which identified a gap within HIV prevention research, which tended to target blacks exclusively. This demonstrated that HIV prevention research in South Africa was partly stratified according to race. The study hence proposed to reverse this trend by focusing on the previously un-researched or under-researched demographics, hence a sample consisting of only whites and Indians. Finally, students were selected instead of staff for purposes of convenience, but also because HIV on some campuses affects students more than it does staff (HESA 2009).

The study comprised 40 purposively sampled participants, roughly divided between white and Indian male students based at Howard College. These were represented in the findings as R1 ('Respondent' 1), all the way up to R40 ('Respondent' 40 ). The total number of participants was arrived at purposively and conveniently. Advance knowledge (Sakarombe 2012) of the white and Indian male population at the colleges was used to constrain selection. For instance, there were roughly equal numbers of white and Indian students to be found lounging at the coffee shop and on the benches outside the $<\mathrm{TB}>$ lecture rooms at any given time. Furthermore, both whites and Indians constitute hard-to-get samples, as evidenced by research done by the HSRC (2002, 2008 and 2010; see also Sakarombe 2012). The two demographies tend to refuse to answer questions pertaining to HIV/AIDS. According to the HSRC study, when researchers conducted door-to-door surveys, most of the respondents refused to open their doors or to complete the questionnaire. This prior knowledge meant that the total number of respondents interviewed was not, in itself, important - what was more crucial was the criteria used to select the sample. In this case, theoretical sampling (Glasser and Strauss 1967) was used, which involved continual sampling, collection and analysis of data up to theoretical saturation. The criteria prioritised were, therefore, based on demographic characteristics (e.g., greater numbers of whites and Indians were more likely to be found in one place by the Howard College coffee shop) and behaviours and attitudes (for instance, hard-to-get sample). The study used an exploratory research instrument to interview participants, who also completed a self-administered semi-structured, exploratory questionnaire. 


\section{Theoretical framework}

To explore knowledge, attitude and perceptions, the study was framed by a combination of public health models, namely the Social Ecology Model (SEM) and the Health Belief Model (HBM), which respectively underpin the social ecology perspective (Bronfenbrenner 1979; Green and Kreuter 2004; McLeroy, Bibeau and Steckler et al. 1988; Sallis and Owen 1997) and the health belief perspective (Glanz, Rimer and Lewis 2002; Hochbaum 1958; Kegeles 1966; Leventhal 1968; Rosenstock 1966). The two theories addressed the theme of what, how and why knowledge, attitudes and perceptions towards a public health issue such as MMC are formed and sustained. It was assumed at the outset that a subject such as medical circumcision for HIV prevention was likely to reflect, on the one hand, a respondent's internal beliefs more so than external forces, such as a campus-wide campaign. On the other hand, attitudes to MMC were likely to also reflect the larger social and racial environment within which white and Indian students move, live and socialise. Not only did these two frameworks overlap, but it also seemed suitable to use them in combination, since health behaviours cannot be fully explained through just a single theory (Eccles et al $2012<$ not in refs $>$; Tomaselli and Chasi 2011).

The SEM was drawn upon in the study in an attempt to understand the social, environmental and racial factors influencing white and Indian male students at UKZN's Howard College in terms of their attitudes and perceptions about MMC as an HIV prevention procedure. The multilevel, concentric and integrated features of the ecological model are sometimes illustrated through the metaphor of the 'Chinese box' (boxes within boxes) or the matryoshka (Russian wooden dolls) (Susser and Susser 1996, 676). The recursive nature of the ecological model (McLeroy Bibeau and Steckler et al. 1988; Sallies $<$ Sallis in refs? >, Owen and Fisher 2008) was crucial in explaining the interrelationship (or lack of one) between attitudes and perceptions towards MMC at UKZN's Howard College and a demographic variable such as race.

In the context of the study, the HBM was taken as the basis for showing that a UKZN white or Indian male student would take a health-related action like MMC if he felt a negative health condition (like HIV infection) could not be avoided (perceived susceptibility); had a positive expectation that by taking the recommended action (MMC) he would avoid the negative health condition (perceived severity); and believed that he could successfully take the recommended health action (perceived benefits). Therefore, an individual's values and beliefs towards health conditions or campaigns such as MMC influenced their behaviour and decision making. The HBM has gradually grown into a well-known theory in health communication in general, and is used in studies of HIV prevention where 'its value as a predictor of long- and short-term health behaviours, including sexual risk behaviours and the transmission of HIV and AIDS' has been demonstrated (Hayden 2009, 31). 


\section{FINDINGS ON KNOWLEDGE}

The two key questions to determine 'knowledge' were: 'Have you heard about MMC?' and 'Describe briefly what you know about MMC.' An additional question, intended to draw attention to cues for action, was: 'Where have you heard about MMC?' Knowledge of MMC as an HIV prevention procedure in the case of the white group was relatively high, with 13 of the 20 participants reporting that they had heard of, or knew about, MMC. The 13 participants had all been exposed to a range of media such as television, billboards and print which mentioned MMC as an HIV prevention procedure. All 13 participants reported having at some point discussed MMC with friends or family. Most participants knew that MMC is an HIV prevention procedure involving some form of 'surgical removal' or 'cutting' of the foreskin, but did not seem willing or able to elaborate on its reported medical effectiveness. Only one of the 13 participants reported knowing that MMC cut infection rates by 60 per cent. Four participants reported that they had neither heard about MMC nor did they know what it was. There was also a further distinction in knowledge, with five participants defining MMC as simply the 'removal of the foreskin', while two defined MMC as the 'surgical' or 'medical' removal of the foreskin. Indeed, one participant reported not knowing much, really, 'except the cutting part'.

Knowledge of the provision of MMC on campus amongst the white participants was low. Only five of the 20 reported having ever heard of the UKZN MMC campaign launched at Howard College in April 2013. The low level of knowledge of the campaign correlated significantly with the low uptake of MMC facilities on campus. This conclusion was backed up by information availed to the researcher in an interview with the coordinator of the campus HIV unit, who confirmed that only one white student had visited the clinic since the start of the campaign, namely for an HIV test. The clinic staff had, however, used the opportunity to talk to him about the campaign. Since the start of the campaign, 43 students have been circumcised - all of them black.

Knowledge of MMC as an HIV prevention procedure in the Indian sample was high. Sixteen participants out of 20 reported that they knew what MMC was and had heard about it prior to the interview. However, only six of the 16 had heard about the MMC campaign at Howard College. Four participants reported never having heard of MMC. Only one of the 20 elaborated on the effectiveness of MMC, specifically its ability to cut infection rates by 60 per cent. Five participants defined MMC simply as 'the removal of the foreskin', compared to three who defined the procedure as the surgical/medical removal of the foreskin. In this sample, knowledge of MMC was varied: some saw it as an HIV prevention procedure, yet others disagreed, seeing it rather as a tool for either genital hygiene or 'better sex'. One participant, for instance, reported that his friends said MMC 'elongates their time when making love'. There is further evidence that knowledge of MMC was not uniform across the data set. One participant, for instance, did not think MMC would work for him as he was not 
HIV positive. This belief conflicted with the view held by another participant who reasoned that MMC was useless for HIV-positive people: 'Those abstaining and those who are already HIV+' would gain little from MMC, in his view. This diversity of knowledge about MMC was characteristic of both the white and Indian student participants.

\section{Discussion of findings on knowledge}

The majority of responses from both samples (white and Indian students) seemed to suggest that the prevailing knowledge of MMC was of a general, limited nature. Inconsistent answers cast doubt on the precise nature of participants' knowledge of MMC. Was this knowledge related to MMC specifically, or male circumcision in general? The responses fail to shed light on this question. It was not clear, moreover, which sets of personal, behavioural, social and environmental aspects amongst the sampled white and Indian students underlaid their low-quality knowledge of MMC and their lack of knowledge about MMC facilities at Howard College. Religion (Jewish, Muslim) and race (white and Indian) seemed to be the only clear factors that were easily associable with knowledge or lack of knowledge of MMC. On the one hand, Jews and Muslims knew about medical circumcision as it relates to their religion, but not in relation to HIV. Those whites and Indians who are neither Jews nor Muslims, on the other hand, did not see the point of knowing about circumcision. The fact that most white and Indian respondents did not know about the link between circumcised and HIV prevention, appeared to explain why both racial demographics generally had a low uptake of MMC. There is a suggestion that that low knowledge correlates with low uptake. Low uptake, on the other hand, may be closely linked to low perceived threat. This point is better illustrated in the findings on attitudes and perceptions towards MMC in the next section.

\section{FINDINGS ON ATTITUDES AND PERCEPTIONS}

The key question on 'attitudes' was the follow-up to the question about whether the respondent was circumcised, which required the respondent to give reasons. Further questions supporting this anchoring question were:

- Should people be medically circumcised to prevent HIV/AIDS?

- Are any of your friends medically circumcised? Why do you think this is so?

- Would you encourage male students to be medically circumcised?

- Would you approve if your friend or brother went for MMC?

- Do you think MMC as an HIV prevention procedure would work for you personally? 
Taken together, all these questions were intended to elicit rich data about attitudes towards MMC as an HIV prevention procedure.

The data on whites showed that only four of the 20 participants had been circumcised. A single respondent returned a questionnaire with 'No comment'. Of the four medically circumcised whites, one had been circumcised for religious reasons, and the other three because they saw MMC as an HIV/STI prevention measure. Fifteen participants were uncircumcised, for a variety of reasons. Nine out of 20 were sceptical about the efficacy of MMC as an HIV prevention procedure and were dismissive of it. Three participants thought MMC was 'pointless' or 'a waste of time', while one was opposed to MMC simply because 'I like my foreskin and I don't want it removed'. Some were more optimistic about the procedure, declaring their willingness 'to try MMC'. One participant, for instance, wanted to try MMC 'as I do not like using condoms'. Interestingly, the preference for MMC over condoms goes against the principle of combination prevention, where $\mathrm{MMC}$ is used in conjunction with condoms.

The number of participants who reported having been medically circumcised was higher in the Indian group: 12 had been circumcised, eight had not. The reasons given, however, vary greatly: ten of the 12 participants had been circumcised for religious or cultural reasons, one had been medically circumcised to prevent STIs, while the other had done it to prevent STIs and 'get a strong penis' for sexual potency. Eight of the Indian participants who were not medically circumcised gave a variety of reasons: a sense of perceived efficacy of safe sex (3 participants), fear of pain (1), privacy concerns (1), doubts (1) and indifference (2).

Broadly, there were 'anti-MMC' and 'pro-MMC' camps within the white and Indian datasets. It seems that students were opposed to MMC for a variety of reasons: three white respondents did not see the point in medically circumcising students; one of four participants in the Indian group used a human rights and ethics perspective to argue that medical circumcision should be an individual choice. 'I like my foreskin and I don't want it removed,' they remarked. The suggestion was that MMC campaigns did not allow individuals to exercise freedom of choice to refuse, since these programmes package MMC as necessary for an HIV-free generation. Two Indian participants were opposed to MMC because 'it is too painful'. Finally, one Indian took the same position as three white students, stating that MMC is a pointless waste of time. Only two whites wanted to be circumcised for HIV prevention.

This 'pro-MMC attitude' was represented by 20 of the 40 participants from both datasets, who advocated that 'all males' should be medically circumcised. One white student was of the opinion that HIV affects everyone, therefore MMC would benefit every UKZN student. The 'Sacco' perception - of HIV as an exclusively black disease - was held by 12 participants from the two datasets. One Indian student, for instance, stated that non-black students would benefit least from MMC because of the low prevalence rate of HUV amongst Indians: 'Indians are not likely to contract HIV.' A white participant agreed that whites would benefit least, because 'they are 
more civilised'. Various beliefs about black students and HIV were reported. For instance, some of the sampled white students claimed:

- 'Most blacks engage in unprotected sex.'

- 'They are at risk.'

- 'They don't believe in MMC but do it traditionally.'

- 'Because most of them are sexually active.'

- 'They're in danger of unprotected sex.'

- 'They cannot control themselves.'

- 'They are prone to more risky sex.'

Some of the sampled Indian group noted the following about black students:

- 'They are promiscuous...'

- 'They mostly do not support condoms.'

- 'They are sexually active.'

- 'They are most affected by HIV.'

- 'They usually have AIDS.'

These reported attitudes openly took race as a marker of disease, and blackness as a sign of being diseased. This attitude was held by a large majority of white and Indian participants, who correspondingly fell into the 'I-don't-see-the-point' attitude category.

\section{Discussion of attitudes and perceptions}

The majority of both Indian and white student responses fell under what we characterise as the 'I-don't-see-the-point' attitude, which corresponds with the 'antiMMC' position. The white and Indian participants did not appear to regard themselves as being at risk of contracting HIV. However, they were also anti-MMC for other reasons, such as the perceived severity of the procedure. Pain, death and the potential loss of pleasure were cited as barriers to MMC by some participants. While there have been assurances that 'trained personnel and correct tools and aseptic conditions can greatly reduce the incidence of post-operative risks' (Auvert, Rain-Taljaard and Lagarde et al. 2003, 315-327), such assurances do not appear to hold sway over the more negative perception that $\mathrm{MMC}$ is painful and potentially fatal. This perception appeared to encourage the formation of specific attitudes towards MMC.

Basically, low perceived threat, high barriers and low perceived benefits, coupled with a heightened sense of perceived severity, appeared to have the effect of suppressing the need to try a recommended behaviour. We regarded the 'I-don't-seethe-point' attitude as reflecting a disinterest in HIV prevention in general and MMC 
in particular among non-black students. Though at one level the 'I-don't-see-thepoint' construct is an attitude, it is also very much an 'action' (or, rather, inaction). Such inaction is reflected in the low numbers that end up considering preventative measures.

The study of perceptions deliberately asked: 'What category/categories of UKZN students should be encouraged to get medically circumcised?' in order to evaluate, (1) perceptions about MMC's target demography and (2) perceptions of MMC itself. The data on perceptions drew three broad sets of perceptions regarding who should be targeted by MMC for HIV prevention: the first set was that male students at Howard College were the target of MMC and that all male students should ideally be medically circumcised because circumcision is a good thing; the second was that students at Howard College should not be circumcised at all because the procedure is not a good thing; and the third set was that MMC was targeted at black students and that it was good for blacks since statistics appeared to show that they were mostly affected by HIV.

The pro-MMC attitude, on the other hand, perceived the procedure as essential in the fight to eradicate HIV. The perception that MMC is good for 'all males' suggests that for some respondents HIV prevention was a gendered issue, not racial. Interestingly, believing that MMC is for 'all males' did not mean that participants could not hold the parallel view that HIV is a 'black disease' (the 'Sacco attitude'). There were clear suggestions from many participants that belonging to a certain race lowered the sense of perceived susceptibility to HIV, while also affecting cues to action and the sense of perceived severity. The data seem to show that a white or Indian male student at UKZN will take a health-related action like MMC only if he feels that a negative health condition (like HIV infection) cannot be avoided; if he has a positive expectation that by taking the recommended action (MMC) he will avoid the negative health condition; and if he believes he can successfully take the recommended health action. There seemed to be a correlation between knowledge, attitudes and perceptions and 'action'. However, correlation was not causation, and it was next to impossible to prove causation.

\section{CONCLUSION}

Two conclusions could be reached from the data: (1) the white and Indian students who participated in the study did not appear to regard themselves as at risk of contracting HIV, hence the 'I-don't-see-the-point' attitude. A low-perceived threat, high barriers and low perceived benefits appeared to have the effect of suppressing the need to try a recommended behaviour; and (2) the participants cared about disease prevention, but distrusted MMC as an efficacious HIV prevention procedure. In general, it was easy to see that the challenge of uptake is much greater amongst non-blacks than amongst blacks. What this study was able to prove, in large part, was a correlation between knowledge, attitudes and perceptions and 'action'. The low 
uptake seems correlated, on the one hand, to low perceived threat and, on the other hand, to negative attitudes towards MMC. Correlation is not, however, causation. It was next to impossible to prove causation. There was no way of showing, with any degree of certainty or precision, that low perceived benefits caused the low uptake of MMC by whites and Indians at Howard College. It was difficult to say what caused such low uptake beyond the fact that this pattern was prominent amongst both whites and Indians. When this data is compared with studies such as Naidoo, Dawood and Driver et al. (2005), it appears that the pattern of low or non-existent uptake is largely exclusive to whites and Indians. By far the most important baseline finding is that a large majority of white and Indian participants fall into the 'I-don'tsee-the-point' attitude category.

It was found that some participants deemed MMC to be a preventive strategy targeted solely at black UKZN students. The perception that white and Indian male students are not at risk of HIV is relatively widespread, while, by extension, the perception that HIV prevention strategies in general and strategies such as MMC in particular are meant for black students is widely held. More detailed analysis showed that a majority of participants have a positive perception of the procedure, as long as it is not performed on them. The dataset showed that gender and race (and to some extent age) are not only important but are interrelated and nested. The implication of this assumption was that variables such as race had an influence on knowledge, perceptions and health behaviours. There were unavoidable interrelationships between knowledge, attitudes and perceptions on the one hand, and race on the other. In turn, this interrelationship was determined by a mix of factors, ranging from highly individualised reasons for wanting (or not wanting) to be medically circumcised, to reasons based on peer group influences, and so on. Hence race as a variable was adopted as a starting point for investigating attitudes and perceptions, not because the researcher blamed or was targeting race in isolation from other factors.

In the end, knowledge, attitudes and perceptions are not metric units but social forms. The search for causes behind knowledge, attitudes and perceptions go beyond simple and isolated explanations of health and disease. This study nevertheless pointed to something far more important: that research into knowledge, attitudes and perceptions of health and disease is an important starting point, which needs to be accompanied by even more robust explanatory frameworks and models. The study appears to indicate that the beliefs of white and Indian students regarding HIV prevention in general and MMC in particular are too complex to be represented by the simplistic image of an oval egg made up of nested and interconnecting levels, or by a simple correlation between health and belief. Rather, the responses showed that the racial and gendered identities of white and Indian students are mere tips of the iceberg, and that the situation beyond the tip is necessarily always in flux, such that the causes of the health beliefs students hold need to be investigated beyond this 
'snapshot'. The true causes of the students' health beliefs are to be found within the larger flux of contradictions and complexities of South African society.

The study observed that the association of HIV with a specific race is both a sad fact and a sign of enduring prejudice and stigma. The study therefore recommends that such stigma be dealt with through critical health communication strategies and approaches that (1) question the social reproduction of stigma and (2) are race sensitive. It is the researchers' view that critical sensitivity to the complexities of race in public health communication has the potential to radically minimise the reproduction of distorted knowledge, attitudes and perceptions of certain races as natural bearers of deadly viruses. In part, this critical sensitivity may be achieved through consciously taking the search for the reasons behind the production and reproduction of knowledge, attitudes and perceptions - in real-life everyday contexts - beyond simple and isolated explanations of health and disease.

\section{REFERENCES}

Auvert, B., R.C. Rain-Taljaard, E. Lagarde, D.J. Taljaard, C. Campbell, C. MacPhail and B. Williams. 2003. Potential for an intervention based on male circumcision in a South African town with high levels of HIV infection. AIDS Care 15(3): 315-3<2? >3.

Bashford, A. 2004. Imperial hygiene: A critical history of colonialism, nationalism and public health. New York: Palgrave.

Bashford, A. and C. Hooker. 2001. Contagion: Historical and cultural studies. London: Routledge.

Bronfenbrenner, U. 1979. The ecology of human development: Experiments by nature and design. Cambridge: Harvard University Press.

Denzin, N. and M. Lincoln. 2005. On elephants and gold standards. Qualitative Research 10: $269-272$.

Eccles $<>$

Ghauri $<>$

Glanz, K., F.M. Lewis and B.K. Rimer. 2002. Linking theory, research and practice. In Health behavior and health education: Theory, research and practice, ed. K. Glanz, F.M. Lewis and B.K. Rimer, <pages>. San Francisco: Jossey-Bass.

Green, L.W. and M.W. Kreuter. 2004. Health program planning: An educational and ecological approach. New York: McGraw-Hill.

Hayden, J. 2009. Introduction to Health Behavior Theory. USA: Jones and Bartlett.

HEAIDS. 2010a. HIV prevalence and related factors - higher education sector study, South Africa, 2008-2009. Pretoria: Higher Education South Africa.

HEAIDS. 2010b. HIV/AIDS prevention good practice: Strategies for public higher education institutions (HEIs) in South Africa. Pretoria: Higher Education South Africa.

Higher Education South Africa (HESA). 2008. HIV and AIDS in the higher education sector: Findings of the study on HIV seroprevalence and related factors at the University of KwaZulu-Natal. Pretoria: HESA. 
Hochbaum, G. 1958. Why people seek diagnostic x-rays. Public Health Reports 71: 377-380.

Holborn, L. 2010. The long shadow of apartheid: Race in South Africa since 1994. Johannesburg: South African Institute of Race Relations.

Human Sciences Research Council (HSRC). 2002. Nelson Mandela/HSRC study of HIV/AIDS: South African national HIV prevalence, behavioural risks and mass media. South Africa: HSRC. http://www.wsu.ac.za/hsrc/html/2007-2.pdf (accessed August 27, 2013).

HSRC. 2005. Describing the structure and needs of families in South Africa: Towards the development of a national policy framework for families. Child, Youth and Family Research Programme.

http://www.hsrc.ac.za/research/output/outputDocuments/2883_Amoateng_Describingthe structure.pdf (accessed June 5, 2013).

HSRC. 2008. Public attitudes in contemporary South Africa. http://www.hsrcpress.ac.za/product. php?productid=2025 (accessed June 17, 2013).

HSRC. 2009. South African National HIV, Behaviour and Health Survey. http://www.hsrc.ac.za/ research/output/outputDocuments/2883_Amoateng_Describingthestructure.pdf (accessed < $>$ ).

Kincaid, D.L. and W. Parker. 2008. National AIDS communication programmes, HIV prevention behaviour, and HIV infections averted in South Africa, 2005. Pretoria: JHHESA.

McLeroy, K.R., D. Bibeau, A. Steckler and K. Glanz. 1988. An ecological perspective on health promotion programs. Health Education Quarterly 15(4): 351-377.

Naidoo, D. 2005. Stigma, denial and discrimination in the era of the HIV/AIDS pandemic. An HSCR report. www.hsrc.ac.za/en/research-data/ktree-doc/3068 (accessed May 16, 2013).

Naidoo P.V., F. Dawood, C. Driver, M. Narainsamy, S. Ndlovu and V. Ndlovu. 2012. Knowledge, attitudes and perceptions of pharmacy and nursing students towards male circumcision and HIV in a KwaZulu-Natal University, South Africa. African Journal of Primary, Health Care \& Family Medicine 4(1): <pages>.

Peltzer, K. and M. Mlambo. 2012. Prevalence and acceptability of male circumcision among young men in South Africa. Ethno Med 6(3): 179-186.

Ronson, J. 2015, February 12. How one stupid tweet blew up Justine Sacco's life. http://mobile. nytimes.com/2015/02/15/magazine/how-one-stupid-tweet-ruined-justine-saccos-life. htmml? referrer $=($ accessed $<>)$.

Ronson, J. 2015. So you have been publicly shamed. London: Picador.

Rosenstock, I. 1974. Historical origins of the Health Belief Model. Health Education Monographs 2(4): $<>$.

Rosenstock, I.M., V.J. Strecher and M.H. Becker. 1988. Social Learning Theory and the Health Belief Model. Health Education Behavior 15(2): 175-183.

Sakarombe, P. 2012. Knowledge, attitudes and perceptions of medical male circumcision as an HIV prevention procedure by white male students at Howard College. Honours mini project, University of KwaZulu-Natal.

Sallis, J.F. and N. Owen. 1997. Ecological models. In Health behavior and health education: Theory, research and practice, ed. K. Glanz, F.M. Lewis and B.K. Rimer, 403-424. San Francisco: Jossey-Bass. 
Shisana, O., T. Rehle, L.C. Simbayi, K. Zuma, S. Jooste, V. Pillay-vanWyk, N. Mbelle, J. van Zyl, W. Parker, N.P. Zungu, S. Pezi and the SABSSM III Implementation Team. 2002. South African national HIV prevalence, incidence, behaviour and communication survey: $A$ turning tide among teenagers? Cape Town: HSRC Press.

Shisana, O., T. Rehle, L.C. Simbayi, K. Zuma, S. Jooste, V. Pillay-vanWyk, N. Mbelle, J. van Zyl, W. Parker, N.P. Zungu, S. Pezi and the SABSSM III Implementation Team. 2005. South African national HIV prevalence, incidence, behaviour and communication survey: A turning tide among teenagers? Cape Town: HSRC Press.

Shisana, O., T. Rehle, L.C. Simbayi, K. Zuma, S. Jooste, V. Pillay-vanWyk, N. Mbelle, J. van Zyl, W. Parker, N.P. Zungu, S. Pezi and the SABSSM III Implementation Team. 2008. South African national HIV prevalence, incidence, behaviour and communication survey: A turning tide among teenagers? Cape Town: HSRC Press.

Shisana, O., T. Rehle, L.C. Simbayi, K. Zuma, S. Jooste, V. Pillay-vanWyk, N. Mbelle, J. van Zyl, W. Parker, N.P. Zungu, S. Pezi and the SABSSM III Implementation Team. 2009. South African national HIV prevalence, incidence, behaviour and communication survey: A turning tide among teenagers? Cape Town: HSRC Press.

Susser, M. and E. Susser. 1996. Choosing a future for epidemiology, <part?> II: From black box to Chinese boxes and eco-epidemiology. American Journal of Public Health 86(5): 674-677.

Tomaselli, K. and C. Chasi, eds. 2011. Development and public health communication. Cape Town: Pearson. 